Revista aSEPHallus de Orientação Lacaniana

Núcleo Sephora de Pesquisa sobre o Moderno e o Contemporâneo

ISSN 1809 - $709 \mathrm{X}$

Psicanálise aplicada ao contexto hospitalar: intervenções em tempos de pandemia Covid-19

Fernanda Saboya R. Almendra

Orcid: https://orcid.org/0000-0001-8429-9705

Coordenadora do Serviço de Psicologia dos Hospitais Copa D’Or, Copa Star, Glória D’Or e Pró-criança Jutta Batista (Rio de Janeiro, Brasil)

Especialista em Psicologia Médica pela FCM-UERJ (Rio de Janeiro, Brasil) Membro do Instituto Sephora de Ensino e Pesquisa de Orientação Lacaniana (Rio de Janeiro, Brasil) Presidente do Departamento de Psicologia da Associação de Medicina Intensiva Brasileira /AMIB, gestão 2020-2021 (São Paulo, Brasil) Email: Fernanda_saboya@yahoo.com.br

Tania Coelho dos Santos

Orcid: https://orcid.org/0000-0002-5360-7864

Supervisora dos Serviços de Psicologia dos Hospitais Copa D'Or, Copa Star e Glória D'Or e Prócriança Jutta Batista, Samaritano de Botafogo e Américas (Rio de Janeiro, Brasil) Presidente do Instituto Sephora de Ensino e Pesquisa de Orientação Lacaniana / ISEPOL (Rio de Janeiro, Brasil)

Pós-doutorado no Departamento de Psicanálise de Paris VIII (Paris, França) Professor Associado, nível IV no Programa de Pós-graduação em Teoria Psicanalítica / UFRJ (Rio de Janeiro, Brasil)

Pesquisadora do CNPQ nível $1 \mathrm{C}$

Psicanalista Membro da École de La Cause Freudienne (Paris, França), da Escola Brasileira de Psicanálise (São Paulo, Brasil) e da Associação Mundial de Psicanálise (Paris, França) Membro da Associação Universitária de Pesquisa em Psicopatologia Fundamental / AUPPF (Rio de Janeiro, Brasil)

E-mail: taniacs@openlink.com.br

Manuella Itapary Ribeiro Moreira

Orcid: https://orcid.org/0000-0002-3068-8905

Psicóloga do Hospital Copa D'Or e Copa Star (Rio de Janeiro, Brasil)

Mestre em Teoria Psicanalítica pela Universidade Federal do Rio de Janeiro / UFRJ (Rio de Janeiro, Brasil) Membro Associado do Instituto Sephora de Ensino e Pesquisa de Orientação Lacaniana / ISEPOL (Rio de Janeiro, Brasil) Email: manuitapary@hotmail.com

Maria Gabriela Severiano Ribeiro de Castro

Orcid: https://orcid.org/0000-0002-6353-9586

Psicóloga dos Hospitais Copa D’Or e Pró-criança Jutta Batista (Rio de Janeiro, Brasil) Especialista em Psicologia Hospitalar pela Pontifícia Universidade Católica / PUC-Rio (Rio de Janeiro,

Brasil)

Mestranda em Teoria Psicanalítica pela Universidade Federal do Rio de Janeiro / UFRJ (Rio de Janeiro, Brasil) Membro Adjunto do Instituto Sephora de Ensino e Pesquisa de Orientação Lacaniana (Rio de Janeiro, Brasil)

Email: mariagabriela.severiano@gmail.com 
Resumo: Este artigo apresenta o relato de experiência de psicólogas clínicas de hospitais privados, localizados na cidade do Rio de Janeiro, durante a pandemia do novo coronavírus. Essa prática é alicerçada nos princípios teórico-clínicos da psicanálise aplicada às práticas em instituições hospitalares. Há mais de uma década faz parte dos projetos de psicanálise aplicada do Instituto Sephora de Ensino e Pesquisa de Orientação Lacaniana. Essa experiência aqui relatada é inédita pois, pela primeira vez, foi necessário efetuar o acompanhamento psicanalítico através de recursos virtuais. A potência do dispositivo analítico, ancorado no campo da fala e da linguagem, precisou ser reinventada para alcançar pacientes com Covid-19 e seus familiares. Através de vinhetas clínicas serão apresentadas algumas das dificuldades encontradas nesta nova prática em tempos de pandemia. Esperamos dar testemunho de que zelamos para que a ética e o desejo do analista nos orientassem para fazer bom uso do novo dispositivo.

Palavras-chave: Psicanálise Aplicada; Desamparo; Ferida narcísica; Psicologia Hospitalar.

Psychanalyse appliquée em contexte hospitalier: interventions em période de pandémie de Covid-19: Cet article présente le rapport d'expérience de psychologues cliniciens des hôpitaux privés, principes théorico-cliniques de la psychanalyse et fait partie des projets de psychanalyse appliquée de I'Institut Sephora pour l'Enseignement et la Recherche d'Orientation Lacanienne, depuis plus d'une décennie. A travers des vignettes cliniques seront présentées quelques impasses face à et comment, en temps de pandémie, l'éthique et le désir de l'analyste ont été maintenus.

Mots clés: Psychanalyse appliquée; état de détresse; narcissisme; Psychologie hospitalière.

Applied psychoanalysis in the hospital context: interventions in times os Covid-19 pandemics: This article reports on the experience of clinical psychologists in private hospitals located in the city of Rio de Janeiro during the covid-19 pandemic. This practice is based on the theoretical-clinical principles of psychoanalysis and has been incorporated into the applied psychoanalysis projects of the Instituto Sephora de Ensino e Pesquisa de Orientação Lacaniana (ISEPOL) for over a decade. Through clinical vignettes, the article will present the impasses faced, in times of pandemic, and how the psychoanalyst's ethics and desires were preserved.

Keywords: Applied Psychoanalysis; Helplessness; Narcissism; Hospital Psychology. 
Revista aSEPHallus de Orientação Lacaniana

Núcleo Sephora de Pesquisa sobre o Moderno e o Contemporâneo ISSN $1809-709$ X

\section{Psicanálise aplicada ao contexto hospitalar: intervenções em tempos de pandemia Covid-19}

Fernanda Saboya R. Almendra, Tania Coelho dos Santos, Manuella Itapary Ribeiro Moreira \& Maria Gabriela Severiano Ribeiro de Castro

Na filosofia em Heidegger, é a certeza da morte que coloca para o homem uma questão sobre o tempo. De acordo com Jacques Lacan, psicanalista francês, não é exatamente a morte como finitude absoluta que nos leva a questionar o tempo. É a finitude do sujeito, sua destituição subjetiva sua afânise, isto é, o risco de seu apagamento diante do desejo do Outro. Ainda para Lacan, três momentos escandem o tempo lógico na experiência analítica do inconsciente: 0 instante de ver, o tempo para compreender e o momento de concluir.

No cotidiano de nosso trabalho como psicólogas clínicas de um hospital privado, o campo da fala e da linguagem ensina a distinguir as dimensões do simbólico, do imaginário e do real. Não pode haver clínica do sujeito sem uma clínica do Outro, isto é, clínica da civilização como propôs o psicanalista Jacques Alain Miller. Nossa prática é alicerçada nos princípios teórico-clínicos da psicanálise e há mais de uma década faz parte dos projetos de psicanálise aplicada do Instituto Sephora de Ensino e Pesquisa de Orientação Lacaniana (ISEPOL). O desafio da clínica psicanalítica hoje é a dificuldade diagnóstica e pode ser resumida assim: "Uma questão preliminar se impõe cada vez mais frequentemente a todos aqueles que praticam a psicanálise: o que é isso que se apresenta na clínica em tempos de declínio da lei e da expansão da lógica do não-todo? Serão doenças da mentalidade, novos sintomas ou novas modalidades da psicose?" (Coelho dos Santos, 2005) Esse desafio é muito mais difícil e urgente no exercício da nossa prática no ambiente hospitalar.

Em seu Ato de Fundação da Escola Francesa de Psicanálise, Lacan (1964/2003) apresenta o campo da psicanálise dividido entre o da psicanálise pura e o da psicanálise aplicada. A formação dos analistas, é a tarefa a que se dedica uma seção de psicanálise pura, isto é, práxis e doutrina da psicanálise propriamente dita ou psicanálise didática, não sendo a psicanálise pura em si mesma uma técnica terapêutica. Uma seção de psicanálise aplicada foi estabelecida para abranger a terapêutica e a clínica médica. São admitidos a essa seção sujeitos que possam contribuir para a experiência analítica: pela crítica de suas indicações nos seus resultados - pondo à prova termos categóricos e estruturas por ele introduzidas, sustentando a linha reta da práxis freudiana no exame clínico, nas definições nosográficas e mesmo na posição dos projetos terapêuticos. 0 ISEPOL não é uma associação de psicanalistas. É um instituto de pesquisa de orientação lacaniana que espera de cada um de seus membros que se dediquem à sua formação como analistas. $\mathrm{O}$ que nós recolhemos, entretanto, é a produção teórico-clínica que Ihes seja permitido extrair de sua prática. 


\section{0 instante de ver}

Em março deste ano nos deparamos com uma situação inédita: a pandemia causada pelo novo coronavírus. Testemunhamos o aumento exponencial de uma infecção gravíssima, a Covid19 , que desencadeou o receio do esgotamento de recursos humanos e materiais. O instante de ver é traumático. O choque que esse encontro com o real provocou foi amenizado por nossos encontros em supervisão no ISEPOL que nos permitiram responder de forma ágil, criativa e inovadora. O desejo decidido da direção da Rede D'Or nos proporcionou um grande apoio às nossas iniciativas, permitindo a imediata ampliação da abrangência de nossos serviços, o que foi um fator essencial para a coesão e segurança de nossas ações.

Pacientes contaminados por um vírus desconhecido e capaz de provocar graves reações convocaram o saber médico à busca do melhor tratamento. No início não havia um protocolo estabelecido para atuar frente a esta nova infecção. Era preciso adaptar o uso de medicações tradicionais e, sobretudo, adotar medidas rigorosas de prevenção e controle da disseminação do vírus. Desorientadas diante desta experiência inusitada, as famílias dos pacientes internados pressionavam por atenção e explicações. A exigência de manter distância física as obrigava a um doloroso sacrifício, submetidas de um lado ao sentimento de culpa por abandoná-los e de outro o medo de contaminar-se também.

Nesse cenário traumático de desordem, desconhecimento, dor, medo e culpa era preciso repensar a modalidade de atenção aos pacientes e às suas famílias. Definir estratégias, abordagens, prioridades e fluxos de informação tornou-se uma tarefa urgente. Não seria possível prosseguir utilizando o mesmo dispositivo clínico baseado no atendimento presencial. Naquele momento inicial o atendimento virtual não foi uma escolha, mas a única solução. Ao final de nossa última supervisão presencial, fomos orientadas a solicitar à direção telefones celulares. Nesta ocasião a supervisora nos aconselhou a sugerir também a compra de máscaras caseiras pois os equipamentos de proteção individual eram escassos. Também uma pequena cartilha com orientações aos colaboradores para lidar com a ameaça de pânico foi elaborada e apresentada pela coordenadora do serviço de psicologia. Seguiu-se uma ampla discussão acerca da linguagem adequada para transmitir essas orientações aos médicos e às equipes de enfermagem.

A pandemia traz consigo as imagens que remetem a cenários relacionados com uma peste. As pessoas tendem a perceber seus efeitos como uma praga lançada contra a humanidade pecadora. Durante os atendimentos aos pacientes na unidade hospitalar, inúmeras vezes escutamos a seguinte indagação: Por que eu? Por que essa doença? O que eu fiz de errado? Os significantes que emergem no discurso dos sujeitos permitem destacar a dor e o luto em torno da ferida narcísica, que é consequência do processo de adoecimento. Frente ao fracasso do corpo em resistir à doença, a perda da saúde e a ameaça de morte abalam o narcisismo do sujeito. 
A doença revela a fragilidade do organismo e pudemos testemunhar fortes reações depressivas que indicam a presença de um trabalho de luto pela perda do sentimento de potência fálica que sustenta o amor de si mesmo. A vulnerabilidade do corpo aponta para um limite à potência fálica do eu, impossível de ser ultrapassado, confrontando o sujeito à dimensão real do desamparo. O tratamento médico é complexo e seus resultados não são garantidos. A Covid-19 é uma doença que se manifesta de modo muito individualizado. $O$ fracasso em superá-la pode desencadear sentimentos de raiva, ressentimento, pessimismo e desesperança deflagrando conflitos e até efeitos deletérios ao tratamento.

Ao psicanalista que atua no hospital cabe estar atento à resposta singular que cada um dá ao encontro com o desamparo e com a ameaça de perda. Esta particularidade da manifestação da doença acentuou muito a desordem nas expectativas de cura e desencadeou reações às perdas impostas pela doença muito mais agudas e imprevisíveis. Nosso trabalho durante a pandemia Covid-19 foi marcado pela insegurança acerca de nossos recursos para enfrentar seus efeitos psicopatológicos.

Um dos obstáculos foi, sem dúvida, o isolamento social. É inegável que a presença e o apoio dos familiares têm fundamental importância no processo de recuperação. Entretanto, por medidas de controle sanitário os órgãos governamentais proibiram a visitação aos pacientes contaminados pelo coronavírus. O manejo da intensa angústia das famílias se tornou um desafio para a equipe médica.

Uma significativa parte dos pacientes estava em estado grave, sedado e em uso de ventilação mecânica, com um quadro de saúde que exigia a máxima atenção da equipe médica e de enfermagem. Era preciso transmitir as notícias sobre o estado de saúde do paciente e o tratamento pelo telefone, mas a rotina de exames e cuidado ao paciente era prioritária. As ligações para os familiares costumavam acontecer apenas no período da tarde e contribuíam adequadamente para regular a angústia, o desespero e a dor. Por essa razão entendemos que deveríamos participar daquele processo. Para isso nos organizamos para realizar contatos telefônicos com todas as famílias dos pacientes em isolamento. O objetivo era fornecer informações não médicas, mas que pudessem amenizar a aflição pela espera do boletim médico. Os contatos telefônicos funcionaram não apenas como um dispositivo de acolhimento, mas de identificação de estados de angústia para consequente intervenção sobre o imaginário uma vez que as ameaças ao narcisismo de cada um foram intensificadas frente ao desconhecido da doença e ameaça de perda.

Reconhecemos a relevância de auxiliar cada familiar, mesmo à distância, a se sentir incluído no tratamento pois isso pode facilitar a elaboração da situação vivenciada. A possibilidade de se fazer presente através de palavras é de suma importância. Isto conforta, traz alento e, sem dúvida, é terapêutico. Precisamos adaptar os instrumentos da avaliação psicodiagnóstica que já 
realizávamos sob supervisão na assistência hospitalar para as novas circunstâncias da pandemia. Era importante que as ligações fossem estruturadas de forma a identificar: aspectos psicossociais do paciente e família; características da rede de suporte social; principais laços afetivos; existência de transtornos psicológicos prévios; capacidade de compreensão acerca das informações médicas; expectativas em relação ao adoecimento; estratégias de enfrentamento utilizadas e características do luto antecipatório.

Através de vinhetas clínicas iremos apresentar alguns impasses enfrentados e como, em tempos de pandemia, procuramos sustentar a ética e o desejo do analista. Destacamos o tempo para compreender os transtornos psicológicos prévios que o adoecimento físico encobre e ao mesmo tempo revela à escuta do psicoterapeuta. As três vinhetas que trazemos foram construídas com elementos dos casos clínicos reais e suficientemente distorcidas para não permitir que sejam reconhecidos.

\section{Tempo para compreender}

O primeiro deles é o caso de V. que acabara de se mudar para o Rio de Janeiro a fim de acompanhar o marido (E.) que havia sido promovido no trabalho. E. estava sedado, em condição grave. Ele fazia parte do dito "grupo de risco", pois tinha mais de 60 anos, era hipertenso e diabético. Sem ter amigos ou familiares na cidade, V. encontrava-se sozinha e assustada. Ela temia estar infectada pelo vírus e embora não apresentasse qualquer sintoma, entendia que cabia à equipe do hospital monitorar a saúde dela.

$\mathrm{O}$ discurso de $\mathrm{V}$. era carregado de raiva e insatisfação. Ela criticava a equipe médica e se queixava de não receber informações suficientes. A senhora também se queixava de não ter acesso a imagens do hospital, pois "não conhecia a instituição e imaginava o pior dos cenários". V. se queixava da frequência do boletim médico, duvidava da veracidade das informações e ameaçava formalizar queixas na Ouvidoria. Mesmo com a psicóloga, algumas vezes V. era hostil e irônica.

Compreender que a revolta vela um intenso sofrimento permite sustentar a escuta e não reagir às provocações. Aos poucos foi possível identificar que a fonte da revolta projetada na equipe não se situava numa suposta falta de informações ou desatenção.

V. não estava satisfeita com a mudança para o Rio de Janeiro. Ela achava que o marido devia ter recusado a proposta e lamentava não mais poder acompanhar de perto o crescimento dos netos. Mal chegaram à cidade o marido adoeceu e a deixou só. A fonte de sua revolta parecia ser um luto ainda não elaborado e certo ressentimento em relação ao marido.

Situar o impasse psicológico que já existia antes da pandemia possibilitou que as intervenções permitissem a V., tão pouco instrumentalizada para lidar com o próprio isolamento, falar sobre essas outras perdas ao invés de alimentar a raiva do marido e, consequentemente, da 
equipe. É preciso compreender que a pandemia muitas vezes é um véu que encobre conflitos desencadeados anteriormente e que vão contribuir para alimentar as reações às perdas trazidas pela Covid-19.

O segundo é o caso de N., 62 anos e várias comorbidades, foi internado em condição grave na UTI. As conversas com o filho eram realizadas de maneira constante e ele apresentava uma boa percepção do quadro de saúde do pai. O familiar compreendia a complexidade do caso, mas conseguia manter uma atitude de esperança. Era um rapaz bem sucedido na carreira profissional e costumava formular perguntas que podiam ser facilmente esclarecidas pela psicóloga. Isso o tranquilizava.

No decorrer dos dias, houve uma inversão. Era o familiar quem ligava diariamente para a psicóloga. Nessas ligações, ele transmitia o quadro clínico do pai e relatava as informações médicas com detalhes, repetindo as informações recebidas e traçando comentários sobre o que havia compreendido.

Reconhecendo certa particularidade naquela atitude a psicóloga perguntou como os demais familiares recebiam as informações médicas. O rapaz disse que a sua mãe ficava muito ansiosa e, por essa razão, não conseguiam conversar a respeito. Amparada pela fé religiosa, para aquela senhora, o saber médico nada tinha a acrescentar. Em um momento difícil, de muitas angústias e incertezas, com quem aquele rapaz contava?

Este filho pode dizer à psicóloga em que aspectos sentia falta do pai. Sabemos que o luto se elaborada na medida em que podemos nomear parte por parte o que foi que perdemos. 0 pai deste rapaz era a pessoa cujo afeto sempre esteve presente em sua vida, aconselhando, orientando, ouvindo. Pai e filho tinham a mesma formação profissional e possuíam uma percepção da vida mais atrelada ao pensamento cientifico. A solidão que sentiu junto à sua mãe, apegada com Deus e indiferente às informações médicas lançou-o no desespero. Conseguiu elaborar a solidão e desamparo proveniente da súbita ausência do pai e do fracasso em compartilhar com sua mãe suas inseguranças e incertezas, com a ajuda das intervenções esclarecedoras que a psicóloga pôde fazer.

Na ausência do seu pai e distante do contato com os médicos, o rapaz ligava para a psicóloga e dizia: "agora só você pode me ajudar, porque só você sabe pelo o que nós aqui estamos passando".

O terceiro é o caso de M., 40 anos, que se internou devido a hemorragia digestiva (fezes com sangue). Esse sintoma consistia em uma complicação decorrente de uma doença inflamatória intestinal diagnosticada e em tratamento médico há vários anos. Na avaliação médica inicial não foi possível descartar a existência de infecção por coronavírus. $O$ exame que detecta o vírus foi colhido na emergência e a paciente precisou permanecer em isolamento. 
Seguindo o protocolo do serviço de psicologia para pacientes em condição de isolamento, foi realizado contato com a paciente e a familiar responsável, no caso, a mãe. Os atendimentos de ambas foram realizados por vídeo-chamada. Logo na primeira abordagem a psicóloga pôde identificar que existia um transtorno psicopatológico produzindo uma fragilidade psíquica que era anterior à internação. $O$ adoecimento atual somou-se a ele e a sensação de ameaça abriu espaço para uma desordem psicológica. O transtorno que até então estava contido desencadeou-se.

M. ficara viúva há alguns anos. Nos momentos de crise da doença de base, quando há necessidade de internação hospitalar ou para auxiliar nos cuidados com o filho é com o apoio da mãe que ela conta. A atividade ocupacional de M. também foi impactada pelo diagnóstico da doença crônica. Seu trabalho exigia certo esforço físico, por essa razão precisou ser desviada de função e passou a exercer tarefas exclusivamente administrativas.

Durante os primeiros atendimentos, a paciente expressava um medo enorme de ter contraído a Covid-19. A sua fantasia girava em torno da informação largamente difundida pela mídia de que pessoas que apresentam comorbidades podem não sobreviver à essa nova doença. Concluiu que pelo fato de já ser portadora de doença autoimune, se contaminada pelo novo coronavírus, não aguentaria e acabaria morrendo. Por outro lado, a percepção da boa evolução de seu quadro clínico e dos resultados satisfatórios dos exames contribuíam para deixá-la menos ansiosa.

Infelizmente seu temor virou realidade. Com dificuldade para respirar, M. se sentiu ainda mais ameaçada, o que potencializou a ideia de que ia morrer. A psicóloga observou então uma significativa mudança no comportamento e no discurso de $M$.

Antes da confirmação do Covid-19 M. dizia que não queria preocupar a sua mãe e por isso, ao telefone, procurava sempre parecer positiva. Após a confirmação diagnóstica passou a mandar as seguintes mensagens para a mãe: "Me ajuda, estou sofrendo muito" ou "Preciso de você, vou morrer". O encontro da paciente com o desamparo evidenciou um sofrimento psíquico prévio muito importante e a desestabilizou por completo.

Ao receber aquelas mensagens $D$. foi imediatamente ao encontro da filha. A familiar ignorou as restrições de visita e forçou a entrada no hospital. D. tinha uma atitude desconfiada e desafiadora, além de questionar as condutas médicas. De forma grosseira e intolerante, a mãe exigiu entrar no leito de M. para ter certeza de que sua filha estava sendo bem tratada. De um lado tínhamos uma paciente isolada, desesperada com a certeza que ia morrer e de outro, uma mãe impulsiva, que não respeitava a equipe de saúde que estava cuidando de sua filha.

O trabalho da psicanálise aplicada caminhou por três vias. A identificação da urgência subjetiva foi o primeiro passo. Colocar um ponto de basta na proliferação imaginária de fantasias persecutórias construídas a partir do sentimento de desamparo e mediar as relações entre a paciente, sua família e os profissionais de saúde direcionou as intervenções. 
Embora a doença prévia produzisse um imenso desgaste para o paciente, não se tratava de uma doença fatal. Todo o tempo M. questionava a natureza de sua doença e tinha dificuldade de aceitar sua enfermidade. A doença autoimune surgiu após um período conturbado e estressante da vida de M. O filho ainda era um bebê quando o marido faleceu de forma repentina. Frustrada e enlutada pelas perdas advindas da doença e com um filho pequeno para cuidar, M. ainda precisou fazer o luto do marido.

Naquela época surgiram sintomas de ansiedade que evoluíram para uma síndrome do pânico e M. buscou acompanhamento psicológico e psiquiátrico. No momento em que estava se sentindo melhor, abandonou os tratamentos sem autorização dos profissionais que cuidavam dela.

Neste caso as intervenções giraram em torno da distinção entre o que era realidade e o que era fantasia. O discurso de M. era fantasioso uma vez que nada indicava que seu estado era crítico e muito menos que ela corria risco de morte. Como ainda precisava de oxigênio, mesmo sabendo que seus parâmetros inflamatórios estavam bem melhores, concluía que seu estado clínico era muito grave.

Foi possível interpretar que o medo de $\mathrm{M}$. era o de morrer abruptamente como seu marido. Ao se sentir ameaçada de morte, apresentava um comportamento repleto de raiva, exatamente como sua mãe. A separação mãe/filha imposta pela hospitalização, por outro lado, deflagrou uma desordem generalizada dos afetos e dos comportamentos. Entre essa mãe e essa filha, havia uma relação devoradora e na qual a figura paterna nunca tinha servido como mediação suficiente. As duas exigiam o tempo todo, ser tratadas como exceção. Nenhuma das duas conseguiu levar em consideração as regras instituídas pelo hospital. M. parecia sentir que tinha que ser compensada das perdas que teve ao longo da vida. Para ela e sua mãe, lidar com o real impossível de representar de uma nova doença foi insuportável.

\section{Momento de concluir}

Acolher e avaliar um elevado número de pacientes e familiares durante uma doença de tamanha gravidade e urgência subjetiva generalizada foi um grande desafio. Não recuamos, entretanto. Partimos do princípio que a ameaça de perda associada ao imposto isolamento poderia provocar efeitos desorganizadores em alguns sujeitos ou consistir em um obstáculo ao luto. Era necessário então, de forma ágil e precisa, identificar as fragilidades psicológicas e prevenir a eclosão de conflitos, bem como auxiliar no manejo da angústia.

As intervenções realizadas nos casos dos pacientes e familiares atendidos durante a situação da pandemia do Covid-19, embora sob a particularidade da realização de atendimentos remotos, não diferiu da prática da psicanálise aplicada no contexto hospitalar. O novo dispositivo, considerando que as dificuldades psicológicas trazidas pela pandemia foram imensas, foi muito 
mais uma solução bem sucedida do que um obstáculo à emergência do inconsciente no campo da fala e da linguagem.

O trabalho em hospital nos convoca a responder com responsabilidade e sob a ética do desejo frente ao que é incerto, incalculável e inédito para cada um. Ouvir o que há de singular no caso-a-caso e identificar os pontos de ambiguidade, repetição e contradição no discurso é o que nos possibilita identificar e intervir sobre o nó de angústia para cada sujeito.

\section{Nota:}

1. Instituto Sephora de Ensino e Pesquisa de Orientação Lacaniana (www.http://isepol.com), presidido pela supervisora do serviço e coautora deste artigo Tania Coelho dos Santos

\section{Referências Bibliográficas}

Coelho dos Santos, T. (2001). Quem Precisa de Análise Hoje? O discurso analítico: novos sintomas e novos laços sociais. São Paulo: Bertrand Brasil.

Coelho dos Santos, T. (Org) (2005). Efeitos terapêuticos na psicanálise aplicada. Rio de Janeiro: Contra Capa.

Coelho dos Santos, T. (2005). A prática da psicanálise na civilização sem bússola. In: Efeitos terapêuticos na psicanálise aplicada (pp. 61-93) Rio de Janeiro: Contra Capa.

Coelho dos Santos, T. (2015). Responsabilidade coletiva e responsabilidade subjetiva: saúde é um direito ou um dever? In: Barros, R.M., Darriba, V. (Orgs). Psicanálise e saúde: entre o estado e o sujeito (pp. 11-41). Rio de Janeiro: Companhia das Letras.

Cottet. S. Efeitos terapêuticos na clínica psicanalítica contemporânea in: Coelho dos Santos, T. (Org). (2005). Efeitos terapêuticos na psicanálise aplicada (pp. 11-51). Rio de Janeiro: Contra Capa.

Freud, S. (1996). Edição standard brasileira das obras psicológicas completas de Sigmund Freud (Vol. I, pp. 333-454) Projeto para uma psicologia científica. Rio de Janeiro: Imago (trabalho original publicado em 1895).

Freud, S. (1996). Edição standard brasileira das obras psicológicas completas de Sigmund Freud (Vol. XIX, pp. 75-108) Sobre o narcisismo: uma introdução. Rio de Janeiro: Imago (trabalho original publicado em 1914).

Freud, S. (1996). Edição standard brasileira das obras psicológicas completas de Sigmund Freud (Vol. XIX, pp. 165-222) O inconsciente. Rio de Janeiro: Imago (trabalho original publicado em 1915). 
Freud, S. (1996). Edição standard brasileira das obras psicológicas completas de Sigmund Freud (Vol. XIX, pp. 243-266) Luto e melancolia. Rio de Janeiro: Imago (trabalho original publicado em 1917).

Lacan, J. (1964). Ato de fundação in: Outros Escritos, Rio de Janeiro, Jorge Zahar Eds., 2003

Lebrun, J-P. (2009). Clínica da instituição: o que a psicanálise contribuiu para a vida coletiva. Porto Alegre: CMC Editora.

Saboya, F., Rieffel, E., Costa, F., Medrado, M. (2014). O papel do psicólogo junto aos familiares. In: Kitajima, K. (Org). Psicologia em unidade de terapia intensiva: critérios e rotinas de atendimento (pp.23-36). Rio de Janeiro: Revinter.

Saboya, F., Itapary, M. (2017). Da urgência médica à urgência subjetiva: a responsabilidade institucional e a responsabilidade de cada um. In: Saboya, F. (Org). Psicologia em unidade de terapia intensiva: intervenções em situações de urgência subjetiva (pp.35-44). Rio de Janeiro: Atheneu.

Citação/Citation: Saboya Almendra, F. \& Coelho dos Santos, T. \& Ribeiro Moreira, M.I. \& Severiano Ribeiro de Castro, M.G. (nov. 2019 a abr. 2020). Psicanálise aplicada ao contexto hospitalar: intervenções em tempo de pandemia Covid-19. Revista aSEPHallus de Orientação Lacaniana, 15(29), 92-102. Disponível em www.isepol.com/asephallus. Doi: 10.17852/1809-709x.2020v15n29p92-102

Editor do artigo: Tania Coelho dos Santos.

Recebido/Received: 10/03/2019 / 03/10/2019.

Aceito/Accepted: 10/20/2019 / 20/10/2019.

Copyright: (C) 2019 Associação Núcleo Sephora de Pesquisa sobre o moderno e o contemporâneo. Este é um artigo de livre acesso, que permite uso irrestrito, distribuição e reprodução em qualquer meio, desde que $o$ autor e a fonte sejam citados/This is an open-access article, which permites unrestricted use, distribution, and reproduction in any medium, provided the author and source are credited. 